\title{
Derivation of mouse embryonic stem cells at CEMIB/UNICAMP
}

\author{
Kaique Catarin de Oliveira*, Marcus Alexandre Finzi Corat.
}

\begin{abstract}
The derivation of mouse embryonic stem cells (ESC) produces mouse embryonic stem cells highly proliferative for using in different studies. Due to their totipotence, since researches "in vitro" of undifferentiating or differentiated cells up to "in vivo" transplants and transgenic animal production make them an useful tool in biologic research. In this work, we aim to use new technologies recently reported in the literature to derivate ESC from important mouse strains maintained at CEMIB/UNICAMP and build a cell bank to researches in the future.
\end{abstract}

\section{Key words:}

Embrionic Stem Cell, Cell Derivation, Laboratory Animal.

\begin{abstract}
Introduction
Stem cells may be able of differentiating into all kinds of cells on the body. According to the source, embryonic stem cells (from embryos) and somatic stem cells (from adult tissues) can present different levels of differentiation. Totipotent stem cells (capable of generating an entire individual), pluripotent stem cells (capable of differentiating into endoderm, ectoderm and mesoderm), multipotent stem cells (differentiate into cells of the tissue they belong to - bone marrow stem cells for example) and unipotent stem cells (which differentiate into only one kind of cell). The derivation method lets us produce in the laboratory embryonic stem cells (ESC) with totipotency, giving us versatility to produce from an animal model genetically modified to differentiate a specific cell such as cardiac myocyte to conduce specific studies. We have many mouse strains maintained with important genetic backgrounds. Some of them with more than one genetic variation introduced artificially by transgenic animal technology. Thereby, keep this background for use in the future researches in genetic manipulation or differentiation assays make us to have interest to build an ESC bank in our Center. Recently were described new protocols that can help ESC derivation of even more sensitive mouse strains, which we will take as reference. ESC derivation consists firstly in producing a feeder layer, i.e. fibroblasts extracted from mouse embryos of around 12-13 days of development and mitotically inactivated, which co-culture with stem cells to keep their totipotence throughout the "in vitro" expansion. Then we develop a mouse embryo at the blastocyst stage of 3.5 to 5.5 days of development, and after hatch, we transfer the totipotent inner cells (ESC) on the feeder layer to culture "in vitro". Along, we have to test ESC clones for their totipotency by checking Oct-4 and Nanog expression, being positive we have to freeze in liquid nitrogen.
\end{abstract}

\section{Results and Discussion}

We are in the first steps of the work. After retrieving the embryos with approximately 13 days of gestation, we started the production of the feeder layers by digestion of embryo tissues. The cells were kept on culture to confluence and then split to 10 flasks and expanded. This first expansion is important to stimulate proliferation of the cells and to eliminate others non proliferative cell types, yielding fibroblast as most (Figure 1). We have frozen those cells and checked culture viability after thawed.

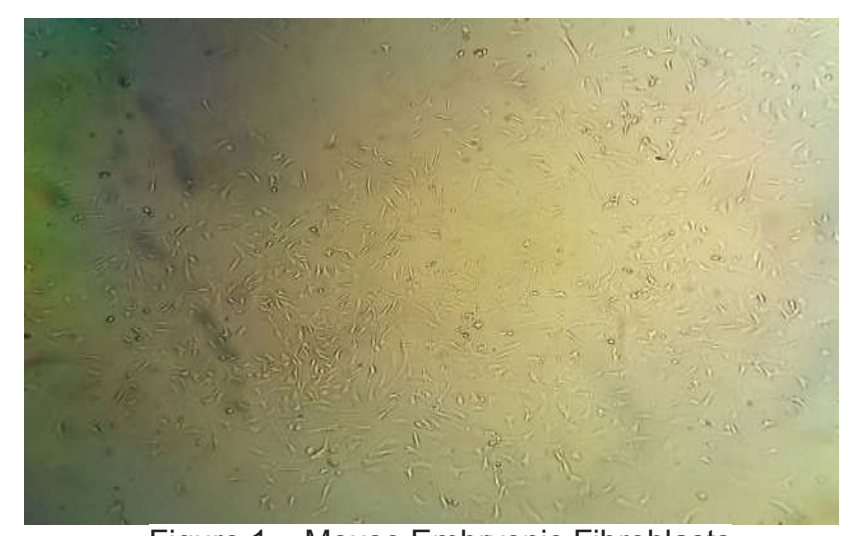

Figure 1 - Mouse Embryonic Fibroblasts

Next step will be to get some 3.5 days mouse blastocyst to hatch the zona pellucida and then separate the inner cells (ESC). They will be cultured on the feeder cells for proliferation and clone expansion. Then, checked by spontaneous differentiation and totipotency using Oct-4 and Nanog expression.

\section{Conclusions}

We are at the beginning of our work and the results are promising. Despite the culture of primary cells being tricky, everything is working well so far. Many steps require care, but we believe it will be successful. The ESC derivation will lead us to developing new tools for our work.

1. Blau, C.A. E. Donnall Thomas, M.D. (1920-2012). Stem Cells Translational Medicine 2, 81-82 (2013).

2. Ittner, L.M. \& Gotz, J. Pronuclear injection for the production of transgenic mice. Nat. Protocols 2, 1206-1215 (2007).

3. Okita, K., Ichisaka, T. \& Yamanaka, S. Generation of germlinecompetent induced pluripotent stem cells. Nature 448, 313-317 (2007).

4. Mummery C, Ward-van Oostwaard D, Doevendans P, Spijker R, van den Brink S, Hassink R, et al. Differentiation of Human Embryonic Stem Cells to Cardiomyocytes. Circulation. 2003;107(21):2733.

5. Czechanski, A. et al. Derivation and characterization of mouse embryonic stem cells from permissive and nonpermissive strains. Nat. Protocols 9, 559-574 (2014). 